Revta brasil. Bot., São Paulo, V.24, n.2, p.161-165, jun. 2001

\title{
Biometria de frutos e sementes e germinação de jatobá-curuba (Hymenaea intermedia Ducke, Leguminosae - Caesalpinioideae)
}

\author{
ENIEL DAVID CRUZ ${ }^{1,3}$, FÁDUA DE OLIVEIRA MARTINS ${ }^{2}$ \\ e JOSÉ EDMAR URANO DE CARVALHO ${ }^{1}$
}

(recebido: 24 de maio de 2000; aceito: 31 de janeiro de 2001)

\begin{abstract}
Fruit and seed biometry and germination of jatoba-curuba (Hymenaea intermedia Ducke, Leguminosae-Caesalpinioideae), Hymenaea intermedia Ducke is a tree species of great load, found in forest areas in the states of Pará and Amazonas, Brazil. The objective of this work was to study the biometrical characteristics of fruits and seeds of $H$. intermedia and the effect of scarification on seed germination. It was measured the length, width and thickness of the fruits and seeds and the number of seeds per fruit. For control and scarified seeds it was measured the percentages and mean time germination and abnormal seedlings and percentage of dead seeds. The seeds scarification was accomplished with an electric emery, in the basal part of the seed. The sowing was done on a substrate of sand and sawdust (1:1), in four replications of 50 seeds, in a complete randomized design. Length, width and thickness of fruits ranged from 26.3 to $54.8 \mathrm{~mm}, 19.1$ to $43.8 \mathrm{~mm}$ and 17.7 to $29.6 \mathrm{~mm}$, respectively. The fruits had from one to three seeds, the percentage of damaged seeds by insects (4.1\%) was low. Length, width and thickness of seeds ranged from 18.7 to 27.4 $\mathrm{mm}, 12.2$ to $16.1 \mathrm{~mm}$ and 10.9 to $15.6 \mathrm{~mm}$, respectively. Statistical difference $(\mathrm{p} \leq 0.05)$ between treatments was detected just for mean germination time. Scarified and control seeds had mean germination time of 18.9 and 68.6 days, germination percentages were $96.0 \%$ and $95.5 \%$, obtained at the $25^{\text {th }}$ and $418^{\text {th }}$ days, respectively. As $H$. intermedia seeds have impermeable tegument to water, mechanical scarification is an efficient method of breaking seed dormancy in this species.
\end{abstract}

RESUMO - (Biometria de frutos e sementes e germinação de jatobá-curuba (Hymenaea intermedia Ducke, Leguminosae-Caesalpinioideae), Hymenaea intermedia Ducke é uma Leguminosae-Caesalpinioideae de grande porte, encontrada em áreas de floresta nos Estados do Pará e Amazonas. O trabalho objetivou estudar as características biométricas de frutos e sementes de H. intermedia e o efeito da escarificação na germinação das sementes. Determinou-se o comprimento, a largura e a espessura de frutos e sementes, o número de sementes por fruto, a porcentagem e o tempo médio de germinação e a porcentagem de plântulas anormais e de sementes mortas, em sementes escarificadas e testemunha. A escarificação foi realizada com esmeril elétrico, na parte basal da semente. A semeadura foi efetuada em substrato de areia e serragem (1:1), em quatro repetições de 50 sementes, em delineamento inteiramente casualizado. Comprimento, largura e espessura dos frutos variaram de 26,3 a 54,8 mm, de 19,1 a 43,8 mm e de 17,7 a 29,6 $\mathrm{mm}$, respectivamente. Os frutos apresentaram de uma a três sementes, sendo baixa $(4,1 \%)$ a porcentagem de sementes danificadas por insetos. Comprimento, largura e espessura das sementes variaram de 18,7 a 27,4 mm, de 12,2 a 16,1 mm e de 10,9 a 15,6 mm, respectivamente. Houve diferença $(\mathrm{p} \leq 0,05)$ entre tratamentos apenas para tempo médio de germinação. Sementes escarificadas e não-escarificadas tiveram tempo médio de germinação de 18,9 e 68,6 dias e porcentagens de germinação de 96,0\% e 95,5\%, obtidas aos 25 e 418 dias, respectivamente. Sementes de H. intermedia apresentam tegumento impermeável à água de modo que a escarificação mecânica é um método eficiente na superação da dormência.

Key words - Mean germination time, dormancy, scarification, Hymenaea

\section{Introdução}

Jatobá-curuba (Hymenaea intermedia Ducke) é uma Leguminosae-Caesalpinioideae, de grande porte, encontrada em áreas de mata de terra firme e margens de rios, nos Estados do Pará e Amazonas (Camargos et al. 1996, Ducke 1949). Embora não haja registro de exploração da madeira de $H$. intermedia, a realização de estudos referentes a essa

1. EMBRAPA Amazônia Oriental, Caixa Postal 48, 66017-970 Belém, PA, Brasil.

2. Faculdade de Ciências Agrárias do Pará, Caixa Postal 917, 66077-530 Belém, PA, Brasil.

3. Autor para correspondência: eniel@cpatu.embrapa.br espécie é importante para a evolução do conhecimento sobre a mesma, uma vez que espécies que hoje são importantes na pauta de exportações do Estado do Pará, como o curupixá (Micropholis venulosa), há cerca de uma década eram pouco exploradas (AIMEX 1998). Convém ressaltar, ainda, que outras espécies do mesmo gênero, tais como $H$. courbaril e $H$. parvifolia, apresentam madeira de boa qualidade e com multiplicidade de usos (Fróes 1959, Souza et al. 1997).

Araújo (1970), realizando estudos fenológicos de várias espécies amazônicas na região de Manaus (AM), classificou $H$. intermedia como uma espécie semi-caducifolia cuja floração ocorre nos meses de julho e agosto, com frutificação nos meses de fevereiro a abril. Entretanto, Knowles \& Parrotta 
(1995), em estudos realizados no oeste do Estado do Pará, citam que a frutificação ocorre nos meses de setembro e novembro.

A caracterização biométrica de frutos e sementes pode fornecer subsídios importantes para a diferenciação de espécies do mesmo gênero. Carpanezzi \& Marques (1981) evidenciaram que o peso das sementes de $H$. courbaril é quase duas vezes superior ao peso das sementes de $H$. parvifolia. A biometria da semente também está relacionada a características da dispersão e do estabelecimento de plântulas (Fenner 1993), sendo também utilizada para diferenciar espécies pioneiras e não pioneiras em florestas tropicais (Baskin \& Baskin 1998). Na maioria dos casos, para as espécies arbustivas e arbóreas existe antagonismo entre o tamanho das sementes e o número de sementes por fruto, conforme observaram Carvalho et al. (1998).

Em sementes de leguminosas tropicais a impermeabilidade do tegumento à água é o mecanismo mais comum de dormência (Rolston 1978), podendo atingir até $98 \%$ das sementes (Cruz et al. 1997). A escarificação, mecânica ou química, constitui um tratamento pré-germinativo eficiente para a superação da dormência em sementes com essa característica, propiciando alta porcentagem de germinação, em curto espaço de tempo (Carpanezzi \& Marques 1981, Martins et al. 1992, Eschiapati-Ferreira \& Perez 1997). Entretanto, Carpanezzi \& Marques (1981) citam que a escarificação com produtos químicos, especialmente ácido sulfúrico, pode se tornar dispendiosa em algumas espécies devido ao tamanho das sementes, sendo necessária a investigação de métodos mais baratos, porém, com eficiência semelhante.

O objetivo do presente trabalho foi estudar as características biométricas do fruto e da semente e o efeito da escarificação mecânica na germinação de sementes de $H$. intermedia, visando determinar o tamanho de frutos e sementes e quantificar a germinação.

\section{Material e métodos}

Frutos maduros de jatobá-curuba (Hymenaea intermedia Ducke, Leguminosae-Caesalpinioideae) foram coletados em floresta nativa, no município de Paragominas $\left(02^{\circ} 57^{\prime} 55^{\prime \prime} \mathrm{S}\right.$ e $47^{\circ} 40^{\prime} 18^{\prime \prime}$ W), Estado do Pará, no mês de outubro de 1998, época seca. As avaliações foram conduzidas no Laboratório de
Ecofisiologia e Propagação de Plantas, da Embrapa Amazônia Oriental, em Belém, Pará. Após a coleta, os frutos permaneceram por três dias em bandejas de plástico, em ambiente com temperatura de $27,5{ }^{\circ} \mathrm{C}$ e umidade relativa do ar de $84 \%$. Após esse período, iniciaram-se as avaliações previstas. Para a remoção das sementes foi necessário quebrar os frutos com auxílio de martelo. A coloração dos frutos e das sementes foi determinada baseada na carta de cores de tecido vegetal (Munsell Color Charts 1977). O comprimento, a largura e a espessura dos frutos e das sementes foram determinados com auxílio de um paquímetro digital, sendo utilizados 100 frutos e 200 sementes. O número de sementes por fruto e a porcentagem de sementes danificadas por insetos foram determinados em uma amostra de 200 frutos e 219 sementes, respectivamente. Considerou-se semente danificada por insetos, aquelas que apresentassem orifício, indicando a presença de adultos ou de larvas em seu interior. A determinação do grau de umidade foi realizada em quatro repetições de dez sementes, adotando-se o método de estufa a $105 \pm 3{ }^{\circ} \mathrm{C}$, durante 24 horas, conforme Brasil (1992). A massa e o volume de 100 sementes foram determinados utilizando-se oito repetições com a mesma quantidade de sementes, sendo o volume determinado através de uma proveta com capacidade para $1000 \mathrm{~cm}^{3}$. Os testes de germinação foram efetuados com sementes escarificadas e não-escarificadas. A escarificação foi efetuada atritando-se levemente a porção basal da semente, durante dois segundos, em superfície abrasiva de esmeril elétrico com $3450 \mathrm{rpm}$. Esses testes foram conduzidos em uma sala nas condições ambientais de Belém (PA). Após a escarificação, as sementes foram imersas em água durante 24 horas e, posteriormente, semeadas em substrato constituído de areia e serragem curtida, previamente esterilizado com água fervente durante duas horas, na proporção volumétrica de 1:1. Os substratos foram irrigados a cada dois dias após a semeadura, sendo realizadas contagens diárias do número de sementes germinadas. O tempo médio de germinação foi estimado segundo Edmond \& Drapala (1958), pela equação:

$$
\mathrm{Tm}=\frac{\mathrm{G}_{1} \mathrm{~T}_{1}+\mathrm{G}_{2} \mathrm{~T}_{2}+\ldots+\mathrm{G}_{\mathrm{n}} \mathrm{T}_{\mathrm{n}}}{\mathrm{G}_{1}+\mathrm{G}_{2}+\ldots+\mathrm{G}_{\mathrm{n}}}
$$

onde, Tm é o tempo médio necessário para atingir a germinação máxima; $\mathrm{G}_{1}, \mathrm{G}_{2}$ e $\mathrm{G}_{\mathrm{n}}$ é o número de sementes germinadas nos tempos $\mathrm{T}_{1}, \mathrm{~T}_{2}$ e $\mathrm{T}_{\mathrm{n}}$, respectivamente. Consideraram-se como germinadas sementes que deram origem a plântulas normais, ou seja, com todas as suas estruturas essenciais bem desenvolvidas, completas, proporcionais e sadias. Foram determinadas também as percentagens de plântulas anormais e de sementes mortas, as quais foram identificadas conforme Brasil (1992).

Os testes de germinação foram conduzidos em delineamento inteiramente casualizado com dois tratamentos e quatro repetições de 50 sementes. Realizou-se, para cada variável, análise de variância, para detectar diferenças entre os tratamentos, sendo as médias comparadas através do teste de Tukey ao nível de $5 \%$ de probabilidade.

\section{Resultados e Discussão}

Os frutos de $H$. intermedia são de coloração marrom-clara (2,5YR4/4), quando maduros, enquanto as sementes são de coloração marrom-escura (10R3/2), o que permite 
diferenciá-las das sementes de $H$. courbaril que são de coloração marrom mais escura.

$\mathrm{Na}$ figura 1 são apresentados os dados de biometria dos frutos de $H$. intermedia onde observa-se que o comprimento, a largura e a espessura dos mesmos variaram de 26,3 a $54,8 \mathrm{~mm}$, de 19,1 a $43,8 \mathrm{~mm}$ e de 17,7 a $29,6 \mathrm{~mm}$, respectivamente. A maioria dos frutos apresentou comprimento variando entre 37,4 a $44,7 \mathrm{~mm}$, largura de 22,2 a 28,3 mm e espessura de 22,2 a $25,1 \mathrm{~mm}$. Esses resultados indicam que frutos dessa espécie são menores que os de $H$. courbaril, cujo comprimento varia de 100 a $200 \mathrm{~mm}$, de acordo com Janzen (1975).

O número de sementes por fruto variou de um a três, com porcentagem insignificante de sementes danificadas por insetos (tabela 1). Os insetos encontrados nas sementes eram da ordem Coleóptera, família Curculionidae, gênero Rhinochenus, fato já observado por Whitehead (1976), em outras espécies do mesmo gênero.

Com relação à biometria das sementes, observou-se que o comprimento, a largura e a espessura variaram de 18,7 a $27,4 \mathrm{~mm}$, de 12,2 a $16,1 \mathrm{~mm}$ e de 10,9 a $15,6 \mathrm{~mm}$, respectivamente (figura 2), sendo que a maioria apresentou comprimento variando de 23,1 a $25,2 \mathrm{~mm}$, largura de 14,2 a 15,1 mm e espessura de 13,9 a 15,0 mm. Valores semelhantes foram registrados por Albuquerque (1993) em $H$. courbaril. A massa média de 100 sementes foi de 371,3 g (tabela 1), o que permite inferir que em um quilograma de sementes de $H$. intermedia possa conter 270 sementes, valor este superior ao encontrado para sementes de $H$. courbaril e inferior ao de sementes de H. parvifolia (Carpanezzi \& Marques 1981). O volume de 100 sementes foi de $561,3 \mathrm{~cm}^{3}$.

A porcentagem de germinação das sementes escarificadas e não-escarificadas foi superior a $95,0 \%$ (tabela 2). No entanto, as sementes
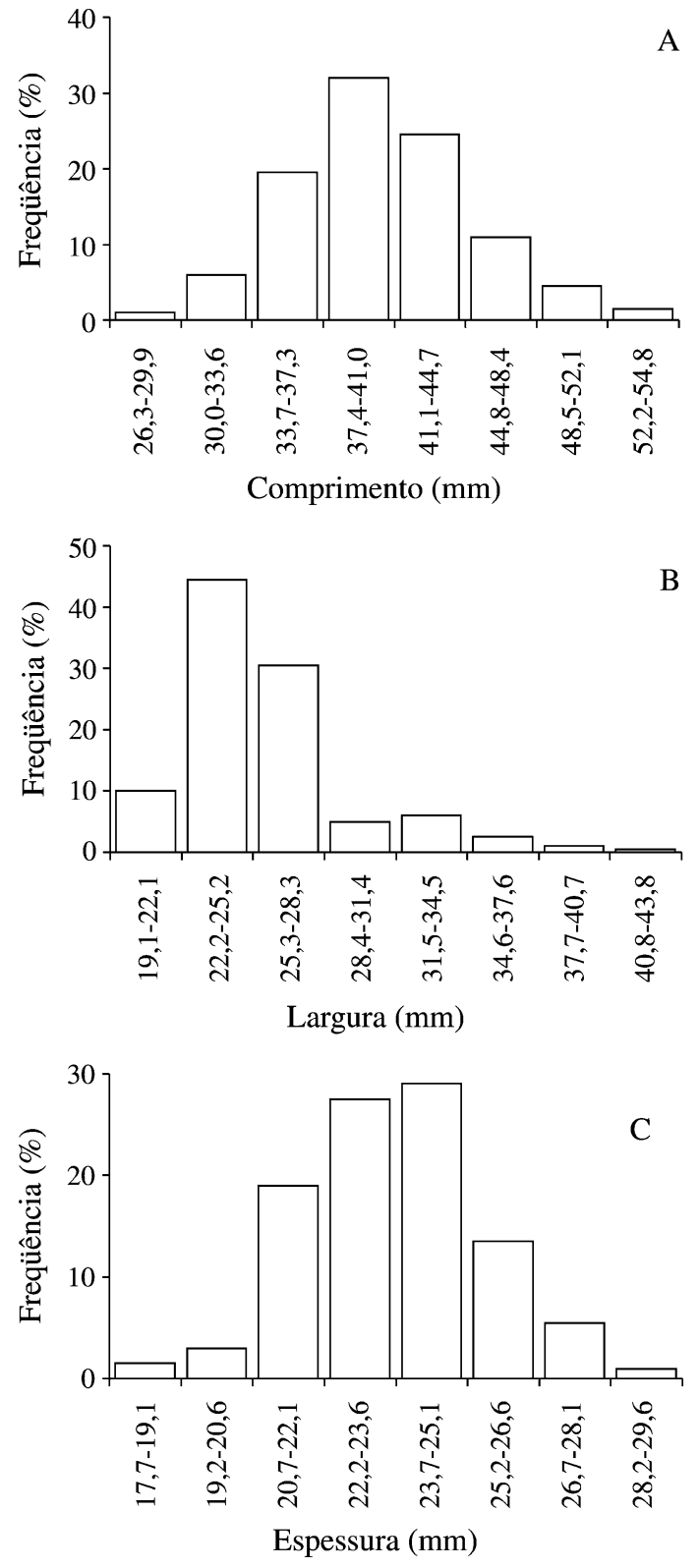

Figura 1. Comprimento (A), largura (B) e espessura (C) de frutos de Hymenaea intermedia.

Tabela 1. Valores mínimo, máximo e médio de algumas características físicas de sementes de Hymenaea intermedia.

\begin{tabular}{lccc}
\hline Característica & Mínimo & Máximo & Médio $^{1}$ \\
\hline Massa de 100 sementes $(\mathrm{g})$ & 364,6 & 375,2 & $371,3 \pm 4,1$ \\
Volume de 100 sementes $\left(\mathrm{cm}^{3}\right)$ & 530,0 & 580,0 & $561,3 \pm 15,5$ \\
Sementes por fruto (número) & 1 & 3 & $1,1 \pm 0,4$ \\
Sementes atacadas por insetos $(\%)$ & - & - & 4,1 \\
\hline
\end{tabular}

1. Valores representam médias e desvio padrão para sementes com grau de umidade de $12,2 \%$. 

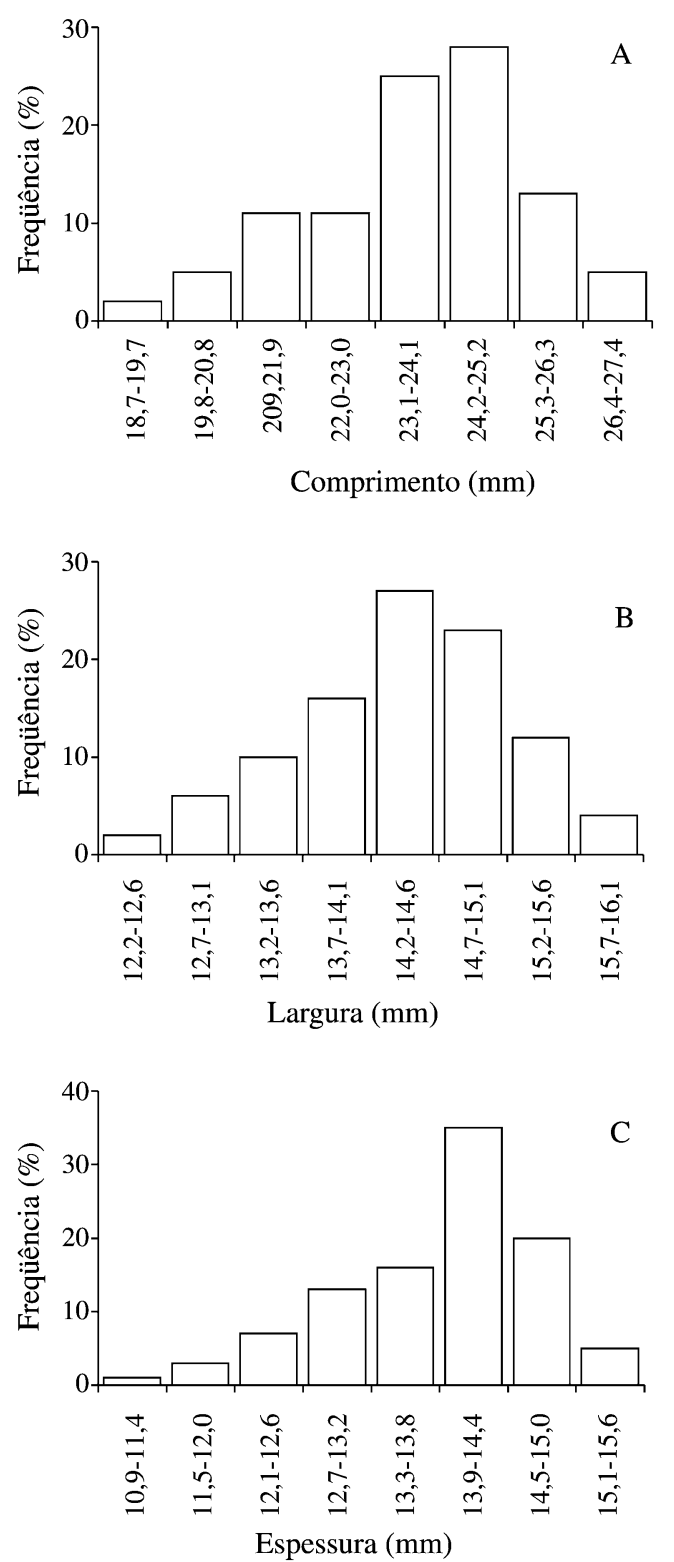

Figura 2. Comprimento (A), largura (B) e espessura (C) de sementes de Hymenaea intermedia.

escarificadas germinaram mais rapidamente, atingindo a máxima porcentagem 26 dias após a semeadura (figura 3), ocasião em que as sementes não-escarificadas apresentaram apenas $51,0 \%$. O patamar superior a $95,0 \%$ de germinação para as sementes não-escarificadas foi atingido somente aos 418 dias após a semeadura (figura 3). A necessidade de longo período para completar a germinação, de
Tabela 2. Efeito da escarificação sobre germinação e tempo médio de germinação em sementes de $H$. intermedia.

\begin{tabular}{lcc}
\hline Tratamentos & Germinação (\%) & $\begin{array}{l}\text { Tempo médio de } \\
\text { germinação (dias) }\end{array}$ \\
\hline Sementes escarificadas & $96,0 \mathrm{a}$ & $18,9 \mathrm{~b}$ \\
Testemunha & $95,5 \mathrm{a}$ & $68,6 \mathrm{a}$ \\
\hline
\end{tabular}

Médias seguidas da mesma letra na coluna não diferem estatisticamente pelo teste de Tukey ( $\mathrm{p} \leq 0,05)$.

sementes de outras espécies do gênero Hymenaea, não submetidas a tratamentos para superação da dormência, também foi observada por Reis et al. (1980), em H. stilbocarpa, e por Garwood (1983), em H. courbaril. Carpanezzi \& Marques (1981) mostram que o uso da escarificação de sementes de espécies do gênero Hymenaea permite obter germinação acima de 90\%. É importante ressaltar que a dormência de sementes também deve ser vista como mecanismo que impede a germinação das sementes em condições inadequadas para o seu desenvolvimento (Fenner 1993). Com relação ao tempo médio de germinação, única variável que apresentou diferença significativa $(\mathrm{p} \leq 0,05)$, observou-se que as sementes escarificadas requereram 18,9 dias para germinar, enquanto que sementes não escarificadas necessitaram de 68,6 dias. Fato semelhante foi registrado por Carpanezzi \& Marques (1981) em sementes de H. courbaril. Convém ressaltar que para sementes como as de $H$. intermedia, que apresentam tamanho grande, o que facilita o manuseio, o método de escarificação pode ser usado para grandes quantidades de sementes e apresenta razoável rendimento de mão-de-obra, possibilitando a escarificação de 1200 sementes em uma hora.

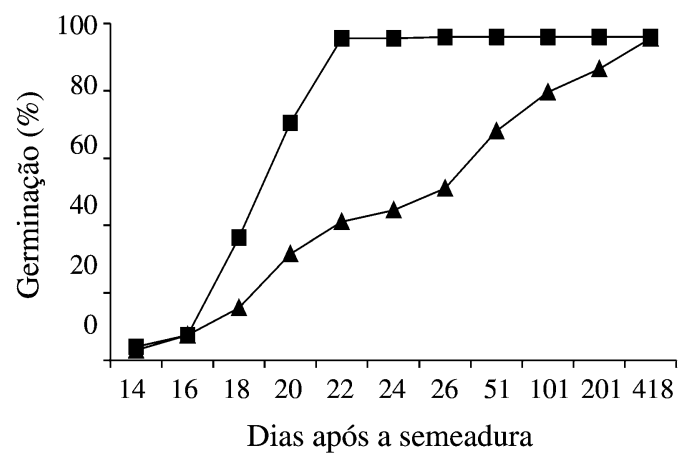

Figura 3. Germinação de sementes escarificadas (ロ) e não-escarificadas ( $\mathbf{\Delta}$ ) de Hymenaea intermedia. 
As baixas porcentagens de plântulas anormais $(2,0$ e $2,5 \%)$ e de sementes mortas $(1,5$ e $2,5 \%)$ nas sementes escarificadas e não escarificadas, respectivamente, mostraram que o método utilizado para a escarificação foi eficiente, não provocando injúrias às sementes.

Esses resultados indicam que nas amostras avaliadas aproximadamente $50 \%$ das sementes de $H$. intermedia apresentaram tegumento permeável à água e que o restante possuía diferentes graus de dormência, o que condiciona acentuada desuniformidade na germinação. Embora a existência de tegumento impermeável seja uma característica indesejável do ponto de vista de manejo, fazendo com que as sementes apresentem resistência à germinação, a mesma também é reconhecida por proteger a semente das flutuações de temperatura, umidade e da incidência de microrganismos (Mohamed-Yasseen et al. 1994). A escarificação mecânica constitui um método eficiente para superar a dormência e promover a germinação de sementes de $H$. intermedia.

\section{Referências bibliográficas}

ALBUQUERQUE, J.M. 1993. Identificação e germinação de sementes amazônicas. Faculdade de Ciências Agrárias do Pará, Belém.

ARAÚJO, V.C. 1970. Fenologia de essências florestais amazônicas. Boletim de Pesquisas Florestais 4, Instituto Nacional de Pesquisas da Amazônia, Manaus.

AIMEX - ASSOCIAÇÃO DAS INDÚSTRIAS EXPORTADORAS DE MADEIRAS DO ESTADO DO PARÁ. 1998. Estatísticas das exportações dos produtos serrados e manufaturados de madeira. Belém.

BASKIN, C.C. \& BASKIN, J.M. 1998. Seeds: ecology, biogeography, and evolution of dormancy and germination. Academic Press, London.

BRASIL. 1992. Ministério da Agricultura e Reforma Agrária. Regras para análise de sementes. Brasília.

CAMARGOS, J.A.A., CZARNESKI, C.M., MEGUERDITCHIAN, I. \& OLIVEIRA, D. 1996. Catálogo de árvores do Brasil. Instituto Brasileiro do Meio Ambiente e dos Recursos Naturais Renováveis, Brasília.

CARPANEZZI, A.A. \& MARQUES, L.C.T. 1981. Germinação de sementes de jutaí-açu (Hymenaea courbaril L.) e de jutaí-mirim (H. parvifolia Huber) escarificadas com ácido sulfúrico comercial. Circular Técnica 19. EMBRAPA-CPATU, Belém.
CARVALHO, J.E.U., NASCIMENTO, W.M.O. \& MÜLLER, C.H. 1998. Características físicas e de germinação de sementes de espécies frutíferas nativas da Amazônia. Boletim de Pesquisa 203. EMBRAPA-CPATU, Belém.

CRUZ, E.D., CARVALHO, J.E.U. \& OLIVEIRA, R.P. 1997. Variabilidade na germinação e dormência em sementes de Centrosema pubescens Benth. Pasturas Tropicales 19:3741.

DUCKE, A. 1949. Notas sobre a flora neotrópica - II. As leguminosas da Amazônia brasileira. 2 ed. Boletim Técnico 18. Instituto Agronômico do Norte, Belém.

EDMOND, J.B. \& DRAPALA, W.J. 1958. The effects of temperature, sand and soil, and acetone on germination of okra seed. Proceedings of the American Society for Horticultural Science 71:428-434.

ESCHIAPATI-FERREIRA, M.S. \& PEREZ, S.C.J.G.A. 1997. Tratamentos para superar a dormência de sementes de Senna macranthera (Collad.) Irwin et Barn. (Fabaceae Caesalpinoideae). Revista Brasileira de Sementes 19:231-237.

FENNER, M. 1993. Seed ecology. Chapman \& Hall, London.

FRÓES, R.L. 1959. Informação sobre algumas plantas econômicas do planalto amazônico. Boletim Técnico 35. Instituto Agronômico do Norte, Belém.

GARWOOD, N.C. 1983. Seed germination in a seazonal tropical forest in Panama: a community study. Ecological Monography 53:159-181.

JANZEN, D.H. 1975. Behavior of Hymenaea courbaril when its predispersal seed predator is absent. Science 189:145-147.

KNOWLES, O.H. \& PARROTTA, J.A. 1995. Amazonian forest restoration: an innovative system for native species selection based on phenological data and field performance indices. Commonwealth Forestry Review 74:230-243.

MARTINS, C.C., CARVALHO, N.M. \& OLIVEIRA, A.P. 1992. Quebra de dormência de sementes de sabiá (Mimosa caesalpiniaefolia Benth.). Revista Brasileira de Sementes 14:5-8.

MOHAMED-YASSEEN, Y., BARRINGER, S.A., SPLITTSTOESSER, W.E. \& COSTANZA, S. 1994. The role of seed coats in seed viability. Botanical Review 60:426-439.

MUNSELL COLOR CHARTS. 1977. Munsell color charts for plant tissues. New York.

REIS, G.G., BRUNE, A. \& RENA, A.B. 1980. Germinação de sementes de essências florestais. Pesquisa Agropecuária Brasileira 15:97-100.

ROLSTON, M.P. 1978. Water impermeable seed dormancy. Botanical Review 44:365-396.

SOUZA, M.H, MAGLIANO, M.M. \& CAMARGOS, J.A.A. 1997. Madeiras tropicais brasileiras. Instituto Brasileiro do Meio Ambiente e dos Recursos Naturais Renováveis, Brasília.

WHITEHEAD, D.R. 1976. Classification and evolution of Rhinochenus Lucas (Coleoptera: Curculionideae: Cryptorhynchineae), and quaternary middle american zoogeography. Questiones Entomologicae 12:118-201. 